\title{
BASTÕES DE GRAFITE RECICLADOS DE BATERIAS COMUNS E SEU USO COMO ELETRODO MODIFICADO EM HIDROGENAÇÃO ELETROCATALÍTICA DE ALGUNS SUBSTRATOS ORGÂNICOS
}

\author{
Renata C. Z. Lofrano, Nei A. Padovan e José R. Romero* \\ Departamento de Química, Faculdade de Filosofia, Ciências e Letras de Ribeirão Preto, Universidade de São Paulo, Av. Bandeirantes, \\ 3900, 14049-901 Ribeirão Preto - SP
}

Recebido em 7/11/01; aceito em 19/6/02

\begin{abstract}
GRAPHITE STICKS RECYCLED FROM COMMON BATTERIES AND THEIR USE AS A MODIFIED ELECTRODE IN ELECTROCATALYTIC HYDROGENATION OF SOME ORGANIC SUBSTRATES. This paper presents some results on the employ of recycled graphite electrode obtained from used common $1.5 \mathrm{~V}$ batteries in the preparation of modified electrode and the electrocatalytical hydrogenation of benzaldehyde and of $n$-valeraldehyde. This inexpensive and easy to obtain electrode was prepared by coating it with a 1:1 mixed film of poly-(allylfenil ether): poly-[allyl p-(2-ethylammonium) benzene ether] and introduction of dispersed platinum particles by ion exchange and reduction of $\mathrm{PtCl}_{4}^{-2}$. Electroreduction of $\mathrm{H}^{+}$from aqueous $\mathrm{H}_{2} \mathrm{SO}_{4}$ using the proposed electrode hydrogenated the substrates in a way comparable with that of vitreous carbon electrode.
\end{abstract}

Keywords: graphite electrode from common batteries; electrocatalytical hydrogenation; modified electrode.

\section{INTRODUÇÃO}

Os métodos de hidrogenação eletrocatalítica de substratos orgânicos ganharam interesse nos últimos anos graças aos eletrodos modificados por filmes poliméricos que contêm partículas de metais de transição como $\mathrm{Pt}$ ou $\mathrm{Pd}^{1-5}$ dispersos. A redução do $\mathrm{H}^{+}$de uma solução de ácido mineral diluído, mediante a aplicação de um potencial catódico, produz $\mathrm{H}$ que é adsorvido na superfície do metal juntamente com a insaturação da molécula orgânica ${ }^{6}$. Compostos carbonílicos e olefinas, entre outros, podem assim ter suas duplas ligações saturadas com hidrogênio. Esta metodologia é interessante porque dispensa a utilização de gás hidrogênio, muitas vezes utilizado sob pressão.

Os filmes mais comuns são polipirróis e derivados, polipiridina e politiofeno ${ }^{3,4}$, viologênio ${ }^{4}$ e Nafion ${ }^{7}$. A metodologia corrente usada para dispersar as partículas metálicas no filme é a troca iônica envolvendo os sais de metal de transição e sua redução eletroquímica ao estado de oxidação zero.

Recentemente, desenvolvemos em nossos laboratórios eletrodos modificados recobertos com filmes obtidos do éter alil fenílico $p$ substituído ${ }^{8}$. A oxidação eletroquímica destes monômeros produz um radical que é o iniciador de uma reação em cadeia, que gera o polímero substituído. Este adere à superfície do eletrodo e se mostrou estável química e mecanicamente. A versatilidade do anel aromático para substituições em para conduz a um filme que pode ser útil tanto para troca iônica de cátions como de ânions. Assim, o poli(éter alil do ácido $p$-benzenossulfônico) pode trocar o íon $\mathrm{H}^{+}$pelo íon $\mathrm{Ni}^{2+}$, que é então reduzido a $\mathrm{Ni}^{\circ}{ }^{9}$. Os percloratos dos poli-(éter alil $p$-anilônio) e poli-[éter alil $p$-(2-etilamônio) benzeno] podem trocar seu contra-íon por $\mathrm{PdCl}_{4}^{2-}$ ou $\mathrm{PtCl}_{4}^{2-}$ e estes serem reduzidos a $\mathrm{Pd}^{\circ}$ ou $\mathrm{Pt}^{\circ}{ }^{10,11}$. No caso de eletrodos modificados por filmes poliméricos contendo partículas de $\mathrm{Pt}^{\circ}$, aldeídos, cetonas e olefinas foram hidrogenadas com bons rendimentos em solução ácida de $\mathrm{HCl}$ ou $\mathrm{H}_{2} \mathrm{SO}_{4}$ mediante aplicação de potencial catódico ${ }^{11}$. O filme misto com o éter alil fenílico, polimerizado juntamente com o perclorato

\footnotetext{
*e-mail: jrromero@ffclrp.usp.br
}

do éter alil p-(2-etilamônio) benzeno na proporção de 1:1, mostrou ser ainda mais eficiente, conduzindo alguns substratos mais volumosos a melhores rendimentos em menores tempos de reação ${ }^{12}$. Esta melhoria deveu-se a um maior espaçamento dos grupos trocadores de íons devido à intercalação do terminal benzeno não-substituído, resultando numa malha polimérica que permite o melhor trânsito do substrato. O eletrodo modificado pode ser reutilizado inúmeras vezes e guardado em dessecador ou em solução de $\mathrm{KCl} 0,1 \mathrm{~mol} \mathrm{~L}^{-1}$ por várias semanas.

O material do eletrodo que serve como suporte para o filme polimérico é uma placa de carbono vítreo. Este material é caro e, embora resistente e durável, é obtido por importação. Neste trabalho, propõe-se a utilização de bastões de grafite natural encontrados no interior de baterias comuns de 1,5 V exauridas (pilhas comuns de rádio $)^{13}$ como suporte para filme polimérico. Com isto, tais baterias podem ser recicladas com um de seus componentes sendo reutilizado a custo zero. Isto é conseguido abrindo-se essas baterias, retirando-se os bastões de grafite contidos nelas e, em seguida, submetendo-os a um processo de limpeza com água e detergente. Este material, apesar de relativamente frágil, é de fácil manuseio e substituição (sem qualquer custo) e apresenta, como será demonstrado nesta nota técnica, desempenho comparável ao dos eletrodos que contêm carbono vítreo como suporte para o filme polimérico para os fins aqui tratados.

\section{PARTE EXPERIMENTAL}

\section{Equipamentos}

A preparação do filme foi feita utilizando uma célula de um compartimento de $100 \mathrm{~mL}$ dotada de eletrodo de trabalho que pode ser uma placa de carbono vítreo de 2,6 x 4,5 x 0,15 cm de espessura ${ }^{11}$ ou quatro bastões cilíndricos de grafite natural com alto grau de pure$\mathrm{za}^{13}$ de $4,5 \mathrm{~cm}$ de comprimento e $8 \mathrm{~mm}$ de diâmetro, conectados num suporte metálico (aço) tal como mostra a Figura 1. O eletrodo de referência foi o de calomelano saturado (ECS) e o auxiliar foi uma rede de platina de $1,0 \mathrm{~cm}$ de altura e $80 \mathrm{~cm}$ de comprimento (espessura do fio de $1 \mathrm{~mm}$ ), enrolado sobre si mesmo como num cilindro, como se pode ver na Figura 1. 
Para as hidrogenações eletrocatalíticas, a rede de platina foi substituída por um fio de platina dentro de um compartimento de vidro com fundo de vidro sinterizado.

Potenciostatos PAR 273 ou MQPG-01 foram utilizados para os experimentos eletroquímicos, com auxílio dos programas computacionais Electrochemical Analysis Model 270 e MQPG, respectivamente.

As medidas de absorção na região do UV-VIS foram feitas com um espectrômetro HP 8453 conectado a um controlador de temperatura Peltier HP 89090A, utilizando-se uma célula de quartzo de $3 \mathrm{~mL}$.

Para a cromatografia a gás foi utilizado um cromatógrafo Intralab 3300 equipado com coluna OV-17 e registrador Intralab 4290.

\section{Preparação do filme misto poli-(éter alil fenílico)/poli-[éter alil $p$-(2-etilamônio) benzeno]}

Em um erlenmeyer de $250 \mathrm{~mL}$ contendo $80 \mathrm{~mL}$ de uma solução 3:7 t-butanol:ácido perclórico $0,5 \mathrm{~mol} \mathrm{~L}^{-1}$ foram dissolvidos $1,6 \mathrm{mmol}$ (349 mg, 0,02 $\left.\mathrm{mol} \mathrm{L}^{-1}\right)$ do éter alil $p$-(2-N-etilacetamida) benzeno ${ }^{11}$. Esta solução foi mantida sob agitação por $2 \mathrm{~h}$ a $60{ }^{\circ} \mathrm{C}$. O material hidrolisado contém as concentrações adequadas de ácido perclórico e do perclorato do éter alílico do 4-(2-amônioetil) benzeno para a realização da etapa seguinte de eletropolimerização (recobrimento do eletrodo pelo filme).

O recobrimento com o filme deu-se por voltametria cíclica usando-se como eletrodo de trabalho os bastões de grafite $\left(9,2 \mathrm{~cm}^{2}\right.$ de área superficial recoberta) ou a placa de carbono vítreo $\left(18,4 \mathrm{~cm}^{2}\right.$ de área superficial recoberta). Foram feitas seis varreduras consecutivas sem agitação entre cada uma, usando-se $70 \mathrm{~mL}$ (1,4 mmoles) da solução $0,02 \mathrm{~mol} \mathrm{~L}^{-1}$ do perclorato do éter alílico do 4-(2-amônioetil) benzeno (monômero) e $0,02 \mathrm{~mol} \mathrm{~L}^{-1}(1,4 \mathrm{mmol}, 187 \mathrm{mg})$ de éter alil fenílico (co-monômero). Nestas condições a proporção monômero:comonômero é de 1:1. O intervalo de potencial utilizado foi de $+0,8$ a $+1,8 \mathrm{~V} v s$. ECS e a velocidade de varredura foi de $10 \mathrm{mV} \mathrm{s}^{-1}$.

\section{Incorporação por troca iônica do íon tetracloroplatinato ao filme}

A placa ou os bastões de grafite recobertos pelo filme misto foram imersos previamente em $30 \mathrm{~mL}$ de solução aquosa $0,5 \mathrm{~mol} \mathrm{~L}^{-1}$ de cloreto de potássio por $30 \mathrm{~min}$. Após a incorporação do íon cloreto ao filme, os eletrodos foram imersos em $30 \mathrm{~mL}$ de solução aquosa $0,01 \mathrm{~mol} \mathrm{~L}^{-1}(125 \mathrm{mg})$ de tetracloroplatinato de potássio por $30 \mathrm{~min}$.

\section{Redução do íon tetracloroplatinato. Formação das partículas de $\mathbf{P t}^{\circ}$}

Os eletrodos contendo os íons tetracloroplatinato foram submetidos a varreduras voltamétricas numa célula contendo $70 \mathrm{~mL}$ de solução aquosa $0,10 \mathrm{~mol} \mathrm{~L}^{-1}$ de cloreto de potássio num intervalo de potencial de $0 \mathrm{a}-1,0 \mathrm{~V} v$ s. ECS a $10 \mathrm{mV} \mathrm{s}^{-1}$.

\section{Caracterização do eletrodo modificado}

\section{Geração de hidrogênio a partir de uma solução de ácido sulfúrico}

Usando-se a placa de carbono vítreo ou os bastões contendo partículas de platina foram feitas varreduras em $70 \mathrm{~mL}$ de solução aquosa $0,10 \mathrm{~mol} \mathrm{~L}^{-1}$ de ácido sulfúrico num intervalo de potencial de 0 a $-1,0 \mathrm{~V} v s$. ECS a $10 \mathrm{mV} \mathrm{s}^{-1}$. Estas descargas de geração de hidrogênio foram comparadas com aquelas dos eletrodos sem o revestimento polimérico e com o filme antes da incorporação da platina (Figura 2). Para se verificar a estabilidade do eletrodo foram repetidas as medidas nos tempos de 24, 48, 72 e 168 h (Figura 5). Durante o intervalo de tempo entre cada medida os bastões modificados foram mantidos imersos em solução de $\mathrm{KCl} 0,1 \mathrm{~mol} \mathrm{~L}^{-1}$.

\section{Determinação da massa de platina nos dois eletrodos}

As massas das partículas de platina incorporadas nos filmes que recobrem a placa de carbono vítreo e os bastões de grafite foram determinadas através do seguinte procedimento: calculou-se a carga consumida para a redução dos íons tetracloroplatinato incorporados ao filme por troca iônica descontando a carga registrada no filme sem o íon tetracloroplatinato, ou seja, antes da troca iônica, utilizando-se os valores fornecidos pelo potenciostato no qual foram realizadas as respectivas varreduras voltamétricas ${ }^{11}$. Conhece-se a carga total que seria necessária para reduzir todo o íon tetracloroplatinato da solução de imersão, porque a sua concentração é conhecida bem como o número de elétrons envolvidos. Pode-se, proporcionalmente, conhecer assim a massa de íon tetracloroplatinato incorporado ao filme, comparando-se estas cargas. Tendo a massa do sal incorporado, calcula-se a massa de platina no filme (Tabela 1$)^{11}$.

Varredura nos intervalos de potencias redox da platina $^{14}$

Para se detectar a presença das partículas de platina no eletrodo modificado foram feitas varreduras em solução de ácido sulfúrico $0,10 \mathrm{~mol} \mathrm{~L}^{-1} \mathrm{de}-0,05 \mathrm{a}+0,5 \mathrm{~V}$ e de $+0,25 \mathrm{a}+0,05 \mathrm{~V} v s$. ECS a $5 \mathrm{mV} \mathrm{s}^{-1}$ (Figuras 3 e 4 ).

\section{Hidrogenação eletrocatalítica de substratos orgânicos}

A hidrogenação eletrocatalítica dos substratos foi feita adicionando-se 3,2 mmol (563 mg, 0,04 $\mathrm{mol} \mathrm{L}^{-1}$ ) do $n$-valeraldeído e 1,6 mmol (173 mg, 0,02 mol L-1) do benzaldeído a uma célula cilíndrica contendo $80 \mathrm{~mL}$ de solução aquosa de $\mathrm{H}_{2} \mathrm{SO}_{4} 0,1 \mathrm{~mol} \mathrm{~L}{ }^{-1}$. Para solubilizar o $n$-valeraldeído utilizou-se uma mistura da solução ácida com etanol na proporção de 1:1. As placas ou os bastões modificados pelo filme misto foram usados como eletrodo de trabalho. Aplicou-se potencial constante de - 0,9V vs. ECS, sob forte agitação magnética, até o final da reação ( 400 min). Observou-se desprendimento de hidrogênio.

Para se acompanhar a reação do benzaldeído, alíquotas da solução foram retiradas no decorrer do tempo e analisadas por espectroscopia na região do UV-VIS em $284 \mathrm{~nm}$. A constante de velocidade desta reação foi obtida diretamente do coeficiente angular da representação do logaritmo neperiano dos valores de absorbância em função do tempo (até pelo menos $2 t_{1 / 2}$, como ilustrado na Figura 6). Para a reação de hidrogenação do benzaldeído também foram feitos estudos em outros potenciais de redução do $\mathrm{H}^{+}$ como - $0,2,-0,3,-0,4,-0,6$ e - $0,8 \mathrm{~V} v s$. ECS, durante o tempo necessário para o decaimento da absorção na região do UV-VIS de pelo menos $1 \mathrm{t}_{1 / 2}$ (Tabela 3).

O meio reacional foi neutralizado com bicarbonato de sódio, em seguida os produtos orgânicos foram extraídos com diclorometano, secos com sulfato de magnésio anidro e o solvente foi evaporado. Após o isolamento, o produto bruto foi pesado e analisado por cromatografia a gás comparando-se com amostra autêntica do $n$-pentanol no caso do n-valeraldeído (Tabela 2) e do álcool benzílico no caso do benzaldeído. O eletrodo de bastão utilizado para a reação com o $n$-valeraldeído foi submetido à experiência de desprendimento de $\mathrm{H}_{2}$ como a apresentada acima no item de caracterização do eletrodo.

\section{Reaproveitamento dos eletrodos}

A placa de carbono vítreo ou os bastões de grafite já recobertos com filme foram polidos com alumina suspensa em água e, em se- 
guida com pasta de diamante. A seguir foram lavados com etanol e depois com água.

\section{RESULTADOS E DISCUSSÃO}

A Figura 1 mostra que os bastões de grafite foram fixados no suporte, introduzindo a sua parte superior num anel de metal cortado de modo a poder regular o diâmetro e prender firmemente o eletrodo. Após o processo de formação do filme, troca iônica e eletrorredução do sal a $\mathrm{Pt}^{0}$, foi feita a caracterização do eletrodo modificado. A Figura 2 mostra que com potencial de $-1,0 \mathrm{~V}$ aplicado à solução ácida ocorre formação de $\mathrm{H}_{2}$ no bastão limpo e no bastão recoberto apenas com o filme, gerando correntes de aproximadamente 350 e $100 \mathrm{~mA}$, respectivamente.

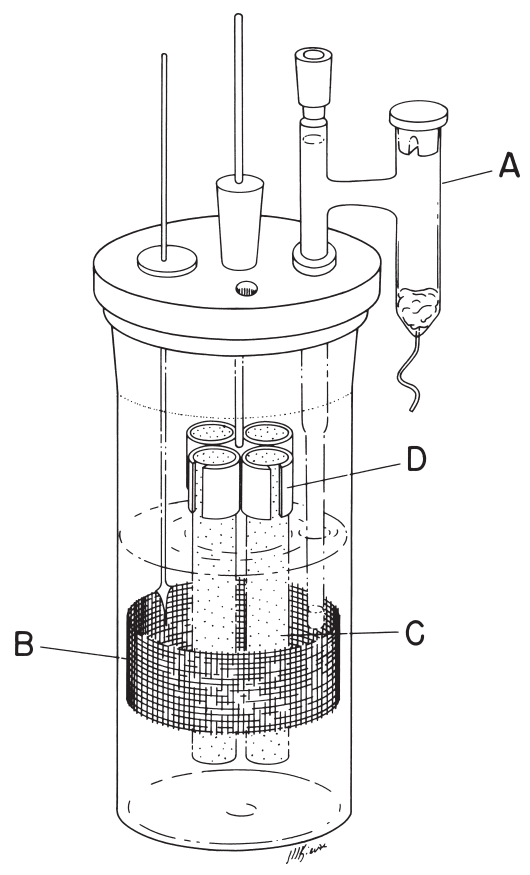

Figura 1. Célula eletrolítica contendo o eletrodo modificado com bastões de grafite. A: eletrodo de calomelano saturado, B: rede de platina, C: bastões de grafite revestidos com o filme tendo partículas de platina dispersas e D: suporte regulável de aço

A massa de platina dispersa no filme do bastão (Tabela 1) é cerca de três vezes maior que a dispersa no filme da placa, calculada a partir da subtração dos coulombs experimentais da redução do íon tetracloroplatinato dos coulombs teóricos da solução de concentração conhecida. A área recoberta pelo filme na placa é, porém, duas vezes maior que no bastão $\left(18,4\right.$ e $\left.9,2 \mathrm{~cm}^{2}\right)$. Assim, o eletrodo com os bastões mostrou ter incorporado mais metal que o eletrodo com a placa. Provavelmente isto se deu devido à maior porosidade dos bastões que permite um recobrimento com quantidade maior de filme.

As correntes de produção do gás $\mathrm{H}_{2}$ com a placa e com o bastão contendo o filme e partículas de Pt dispersas são de 400 e 930 mA, respectivamente (Figura 2). Tendo em conta as massas de Pt incor-

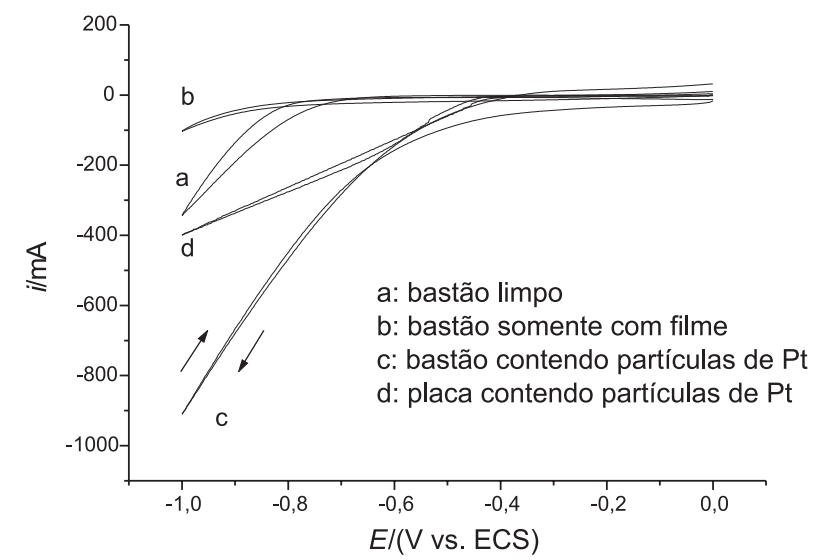

Figura 2. Curvas corrente-potencial obtidas com diferentes eletrodos modificados em solução de $\mathrm{H}_{2} \mathrm{SO}_{4} 0,10 \mathrm{~mol} \mathrm{~L}^{-1}$ a uma velocidade de varredura de $10 \mathrm{mV} \mathrm{s}^{-1}$

poradas nos filmes poliméricos, a eficiência de redução do $\mathrm{H}^{+}$com os bastões ( $145 \mathrm{~mA} / \mathrm{mg}$ de $\mathrm{Pt}$ ) é somente um pouco menor que aquela obtida com a placa de carbono vítreo $(210 \mathrm{~mA} / \mathrm{mg}$ de $\mathrm{Pt})$. As Figuras 3 e 4 mostram os processos de oxidação (do hidrogênio adsorvido e formação de óxido) e redução (do óxido e do hidrogênio adsorvido) que caracterizam a presença das partículas de platina dispersas no filme ${ }^{14}$.

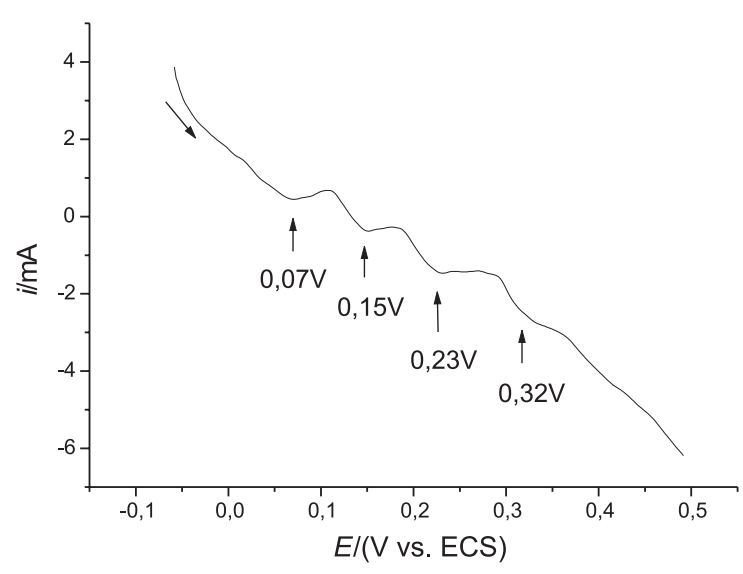

Figura 3. Curva corrente-potencial (varredura anódica) obtida para um eletrodo modificado com bastões de grafite em solução de $\mathrm{H}_{2} \mathrm{SO}_{4} 0,10 \mathrm{~mol} \mathrm{~L} \mathrm{~L}^{-1}$ a uma velocidade de varredura de potenciais de $5 \mathrm{mV} \mathrm{s}-1$

Os potenciais redox assinalados nas Figuras 3 e 4 não são totalmente coincidentes com aqueles descritos na literatura ${ }^{14}$. Isto deve ocorrer porque, dependendo do tamanho, as partículas de platina podem ocupar distintas posições na rede polimérica que recobre o bastão de grafite, levando a possíveis variações nos valores dos potenciais redox quando comparados com aqueles obtidos com um eletrodo maciço e plano de platina. Sendo assim, é de se esperar que ocorram desvios nos valores destes potenciais ${ }^{15}$.

Tabela 1. Massas das partículas de platina incorporadas nos filmes que recobrem os dois eletrodos

\begin{tabular}{ccccc}
\hline Tipo de eletrodo modificado & Área recoberta pelo filme $\left(\mathrm{cm}^{2}\right)$ & Carga $(\mathrm{C})$ & Massa de Pt $(\mathrm{g})$ & Corrente/massa de Pt $(\mathrm{A} / \mathrm{g})$ \\
\hline Placa de carbono vítreo & 18,4 & 1,89 & $1,9 \times 10^{-3}$ & 210 \\
Bastão de grafite & 9,2 & 6,3 & $6,4 \times 10^{-3}$ & 140 \\
\hline
\end{tabular}




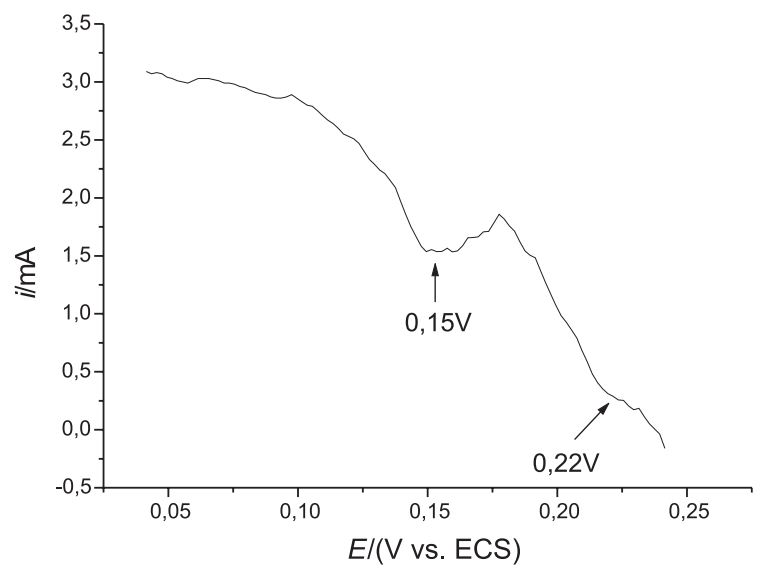

Figura 4. Curva corrente-potencial (varredura catódica) obtida para um eletrodo modificado com bastões de grafite em solução de $\mathrm{H}_{2} \mathrm{SO}_{4} 0,10 \mathrm{~mol} \mathrm{~L}^{-1}$ a uma velocidade de varredura de potenciais de $5 \mathrm{mV} \mathrm{s}-1$

A estabilidade deste novo eletrodo modificado foi testada fazendo-se a varredura voltamétrica na solução ácida e verificando-se a corrente de desprendimento de $\mathrm{H}_{2}$ a -1,0 V durante vários dias. Como se pode ver pela Figura 5, há uma pequena queda da corrente média após sete dias da construção do eletrodo. Uma possível causa para esta queda é a perda de material polimérico carregando as partículas de metal. A flutuação dos pontos pode ser devida a modificações estruturais na rede polimérica durante a permanência do eletrodo na solução de $\mathrm{KCl}$, alterando a permeabilidade dos íons $\mathrm{H}^{+}$. Estabilidade semelhante foi obtida para os eletrodos cujos filmes foram depositados na placa de carbono vítreo ${ }^{11,12}$

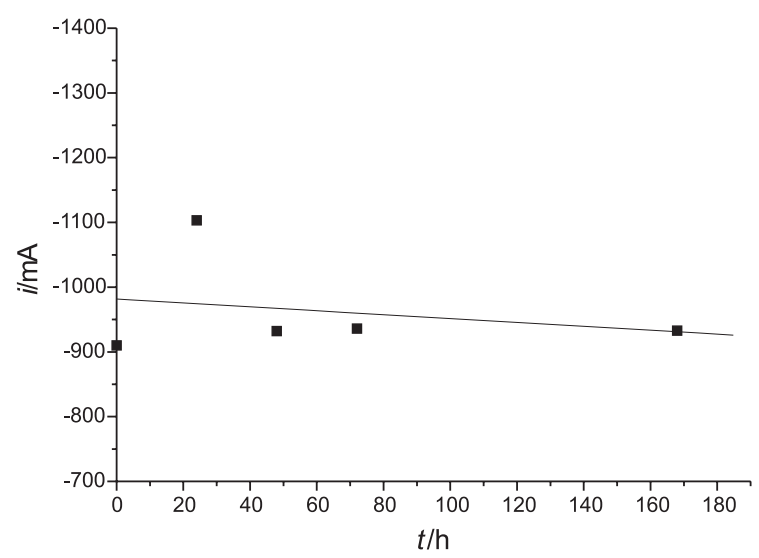

Figura 5. Correntes de desprendimento de $\mathrm{H}_{2}$ obtidas, a -1,0 V (vs. ECS), a partir de curvas corrente-potencial registradas em diferentes tempos para um eletrodo modificado com bastões de grafite em solução de $\mathrm{H}_{2} \mathrm{SO}_{4} 0,10 \mathrm{~mol} \mathrm{~L}^{-1}$ a uma velocidade de varredura de potenciais de $10 \mathrm{mV} \mathrm{s}^{-1}$

A hidrogenação eletrocatalítica do benzaldeído foi acompanhada pelo decaimento da absorção do cromóforo na região do UV-VIS (284 nm) em função do tempo. Dado que a reação é de primeira ordem $^{8,11}$, o coeficiente angular da reta obtida da regressão linear da representação do logaritmo neperiano dos valores de absorbância em função do tempo (Figura 6) é diretamente a constante de velocidade da reação estudada. A Figura 6 mostra a comparação entre os decaimentos do benzaldeído para a placa de carbono vítreo $(8,9 \mathrm{x}$ $10^{-3} \mathrm{~s}^{-1}, 120 \mathrm{~min}$ ) e para o eletrodo construído com os bastões de grafite (2,7 x $\left.10^{-3} \mathrm{~s}^{-1}, 325 \mathrm{~min}\right)$. Embora a velocidade de hidrogenação usando o eletrodo proposto tenha resultado inferior, o rendimento em álcool benzílico foi bastante elevado $(94,9 \%)$ e praticamente o mesmo com aquele obtido com o eletrodo com carbono vítreo $(95,2 \%)$.

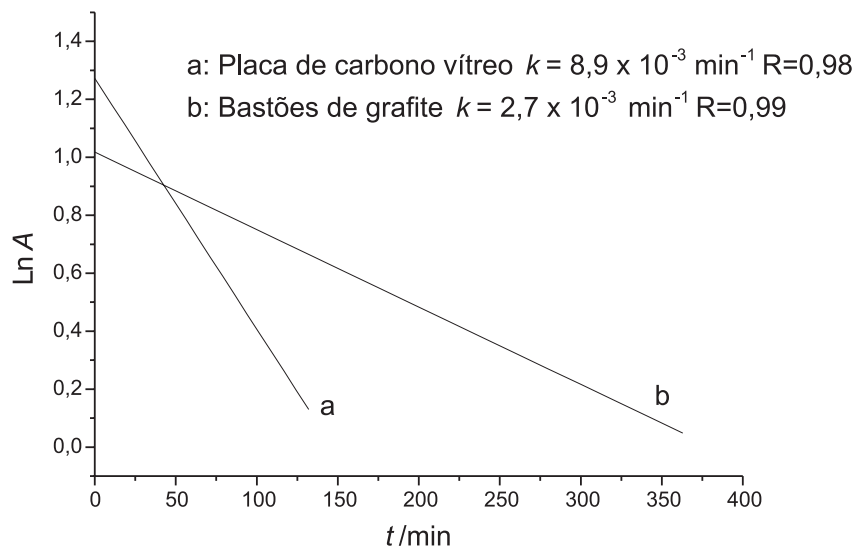

Figura 6. Regressão linear do logaritmo neperiano dos valores de absorbância em função do tempo obtidos, a $284 \mathrm{~nm}$, para a reação de hidrogenação eletrocatalítica do benzaldeído usando diferentes eletrodos modificados

$\mathrm{O} n$-valeraldeído deu como único produto o $n$-pentanol utilizando-se os dois eletrodos em comparação. A Tabela 2 mostra um aumento no rendimento do produto quando o eletrodo com bastão foi utilizado após o mesmo tempo de reação (a transparência do $n$ valeraldeído na região do UV-VIS não permitiu o acompanhamento da reação como no caso do benzaldeído). O uso deste mesmo eletrodo de bastão de grafite para produzir $\mathrm{H}_{2}$ a $-1,0 \mathrm{~V}$ mostrou que ele pode ser reutilizado, pois gerou uma corrente ainda maior $(\approx 1,4 \mathrm{~A})$.

Tabela 2. Rendimento do $n$-pentanol obtido na hidrogenação eletrocatalítica do $n$-valeraldeído após 16 h de reação

\begin{tabular}{lcc}
\hline $\begin{array}{l}\text { Tipo de eletrodo } \\
\text { modificado }\end{array}$ & $\begin{array}{c}\text { Rendimento } \\
\text { cromatográfico }(\%)\end{array}$ & $\begin{array}{c}\text { Rendimento em } \\
\text { massa }(\%)\end{array}$ \\
\hline Placa de carbono vítreo & 75,4 & 70,6 \\
Bastão de grafite & 86,4 & 78,7 \\
\hline
\end{tabular}

A Figura 2 mostra que o desprendimento de hidrogênio começa a valores de potencial menores $(\approx-0,4 \mathrm{~V})$ quando os eletrodos contêm as partículas de platina. Esta diminuição é importante porque significa um aporte menor de energia. Foram aplicados vários potenciais de $-0,2$ a $-0,9 \mathrm{~V}$ para a redução do benzaldeído, utilizandose o eletrodo de bastões de grafite. Compararam-se as velocidades de hidrogenação catalítica até o decaimento da banda em $284 \mathrm{~nm}$ correspondente a $1 \mathrm{t}_{1 / 2}$.

Como indicado na Tabela 3, a -0,2 e -0,3 V não houve apreciável decaimento na banda na região do UV-VIS após 30 min. Para os valores de $-0,4$ e $-0,6 \mathrm{~V}$, as velocidades de hidrogenação do benzaldeído foram significativamente maiores (2 vezes) que o valor obtido a um potencial de $-0,9 \mathrm{~V}$. Este resultado, apesar de ser um pouco menor que aquele obtido a $-0,9 \mathrm{~V}$ usando o eletrodo com placa de carbono vítreo $\left(8,9 \times 10^{-3} \mathrm{~min}^{-1}\right)$, apresenta a vantagem de requerer menores energias (menores valores de potencial). $\mathrm{O}$ fato da constante de velocidade da reação de hidrogenação de benzaldeído 
Tabela 3. Constantes de velocidade obtidas para a reação de hidrogenação eletrocatalítica de benzaldeído usando um eletrodo modificado com bastões de grafite polarizado em diferentes potenciais

\begin{tabular}{ccc}
\hline $\begin{array}{c}\text { Potencial } \\
\text { aplicado } \\
\text { (V vs. ECS })\end{array}$ & $\begin{array}{c}\text { Tempo para o } \\
\text { decaimento de } \\
1 \mathrm{t}_{1 / 2} / \text { min }\end{array}$ & $k / 10^{-3} \mathrm{~min}^{-1}$ \\
\hline$-0,2$ & $-*$ & - \\
$-0,3$ & $-*$ & - \\
$-0,4$ & 90 & 6,1 \\
$-0,6$ & 90 & 6,3 \\
$-0,8$ & 150 & 3,9 \\
$-0,9$ & 210 & 2,9 \\
\hline
\end{tabular}

* Para os potenciais de $-0,2$ e $-0,3 \mathrm{~V}$ a reação foi mantida por $30 \mathrm{~min}$

ter resultado maior para menores valores de potenciais (menor quantidade de hidrogênio produzida) pode estar relacionado a uma maior facilidade de trânsito do substrato pela malha do filme polimérico e, conseqüentemente, de sua adsorção.

\section{CONCLUSÃO}

O reaproveitamento dos ânodos de pilhas comuns usadas, bastões constituídos por grafite de alta pureza, produz um material que pode ser utilizado com vantagens e a custo zero como eletrodos de trabalho. A confecção de eletrodos modificados mostrou-se eficiente para a hidrogenação eletrocatalítica de substratos orgânicos. Dois substratos, benzaldeído e $n$-valeraldeído, anteriormente estudados com vários outros compostos carbonílicos, foram hidrogenados exclusivamente a seus álcoois com bons rendimentos em meio de áci- do sulfúrico. Várias experiências puderam caracterizar o eletrodo e demonstrar que ele possui maior quantidade de partículas de platina que as placas de carbono vítreo, com uma boa estabilidade e reprodutibilidade. Isto ocorreu, possivelmente, devido ás características de superfície dos bastões de grafite que são visivelmente mais porosos que as placas de carbono vítreo, embora menos resistentes a choques mecânicos.

\section{AGRADECIMENTOS}

À FAPESP, CAPES e CNPq pelas bolsas e suporte financeiro.

\section{REFERÊNCIAS}

1. Mertz, A.; Topics in Current Chemistry 1990, 50, 152.

2. Moutet, J-. C.; Org. Prep. Proced. Int. 1992, 24, 309.

3. Deronzier, A.; Moutet, J-. C.; Coord. Chem. Rev. 1996, 147, 339.

4. Moutet, J-. C.; Actual. Chim. 1998, 8-9, 63.

5. Malinauskas, A.; Synth. Met. 1999, 107, 75.

6. Cleghorn, S. J. C.; Pletcher, D.; Electrochim. Acta 1993, 38, 425.

7. Na, W.; Hong, J. K.; Pintauro, P. N.; J. Appl. Electrochem. 1998, $29,94$.

8. Lofrano, R. C. Z.; Madurro, J. M.; Romero, J. R.; J. Mol. Catal. A: Chem. 2000, 153, 237.

9. Pontólio, J. O. S.; Romero, J. R.; Anais do XII Simpósio Brasileiro de Eletroquímica e Eletroanalítica, Gramado, Brasil, 2001.

10. Braghiroli, R.; Bottecchia. O. L.; Madurro, J. M.; Anais do XII Simpósio Brasileiro de Eletroquímica e Eletroanalítica, Gramado, Brasil, 2001.

11. Lofrano, R. C. Z.; Queiroz, J. J.; Romero, J. R.; J. Mol. Catal. A: Chem. 2001, 174, 223.

12. Lofrano, R. C. Z.; Romero, J. R.; trabalho não publicado.

13. http://www.grafite.com/bateria.htm, acessada em Setembro 2001.

14. Bard, E. J.; Faulkner, L. R.; Electrochemical Methods, Wiley: New York, 1980, p. 540.

15. Murray, R. W.; Molecular Design of Electrodes Surfaces. Techniques of Chemistry Series, Wiley: New York, 1992, p. 9. 